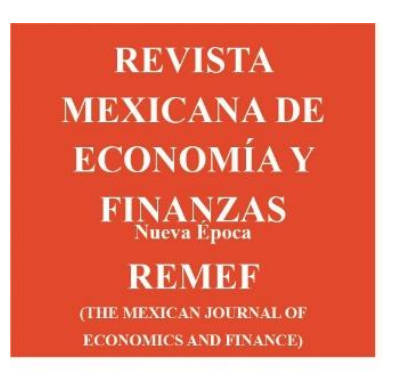

Revista Mexicana de Economía y Finanzas, Nueva Época

Volumen 16 TNEA, September 2021, pp. 1-25, e583

TOPICS IN BANKING AND FINANCIAL INSTITUTIONS

Guest Editor: Dr. Adrián Rossignolo

DOI: https://doi.org/10.21919/remef.v16i0.583

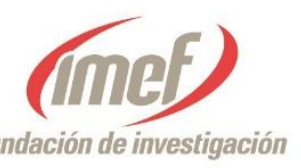

(Received: December 17, 2020, Accepted: June 22, 2021.

Published: August 30, 2021)

\title{
Fuzzy Portfolio Selection with Sugeno Type Fuzzy Neural Network: Investing in the Mexican Stock Market
}

\author{
Judith Jazmin Castro Pérez ${ }^{1}$ - Universidad Tecnológica de México, México \\ José Eduardo Medina Reyes² - Instituto Politécnico Nacional, México \\ Mención Honorifica, Categoría investigación financiera empresarial \\ XXXVI Premio Internacional de Investigación Financiera IMEF-EY 2020
}

The objective of this research is to compare the returns of the portfolios developed by the proposed methodology called Fuzzy Portfolio Selection with Sugeno Type Fuzzy Neural Network against Markowitz's portfolio theory; to identify the best investment model. For this purpose, we used ten stock time series of the Mexican market in daily format from January 2, 2015, to May 15, 2020, to get the portfolios every week from May 15 to June 12, 2020. The principal result is that our methodology recognized the behavior of each share, generates better risk management, and higher returns in comparison with the traditional techniques. The recommendation is to evaluate other stocks and markets to verify the efficiency of our model, the limitation is that a fundamental analysis must precede the tool, and the originality is the new technique proposed. The main conclusion is that the portfolio selection model based on fuzzy neural networks generated two models that do not have negative returns in any week, the cumulative return obtained was up to $15.68 \%$.

JEL Classification: C45, C49, E7, G11.

Keywords: Portfolio Theory; Fuzzy Theory; Fuzzy Neural Network; Financial Markets; Markowitz's Portfolio Theory.

\section{Selección de portafolios difusos con redes neuronales difusas tipo sugeno: invirtiendo en la Bolsa Mexicana de Valores}

El objetivo de esta investigación es comparar los rendimientos de la metodología propuesta denominada como Portafolios Difusos con Redes Neurales Difusas Tipo Sugeno contra la teoría de portafolios de Markowitz; buscando identificar el mejor modelo de inversión. Para ello, se estudian diez acciones del mercado mexicano en formato diario desde el 2 de enero 2015 hasta el 15 de mayo de 2020, con el fin de obtener portafolios de inversión semanales desde el 15 de mayo hasta el 12 de junio de 2020. El principal resultado es que nuestra metodología reconoce el comportamiento de cada acción, genera una mejor gestión del riesgo y proporciona mayor rentabilidad en comparación con las técnicas tradicionales. La recomendación es evaluar otras acciones y mercados para verificar la eficiencia del modelo, la limitación es que un análisis fundamental debe preceder a la herramienta, y la originalidad es la nueva técnica propuesta. La principal conclusión es que el modelo de selección de cartera basado en redes neuronales difusas generó dos portafolios sin rendimientos negativos durante el periodo, la ganancia acumulada obtenida fue de hasta un $15.68 \%$.

Clasificación JEL: C45, C49, E7, G11.

Palabras clave: Teoría de Portafolios; Teoría Difusa; Red Neuronal Difusa; Mercados Financieros; Teoría de Portafolios de Markowitz.

1 Corresponding author. Universidad Tecnológica de México - UNITEC MÉXICO - Campus Querétaro; Email: castro.410210@gmail.com; ORCID: https://orcid.org/0000-0002-3412-2079

${ }^{2}$ ORCID: https://orcid.org/0000-0001-6320-9299

* No source of funding for research development 


\section{Introduction}

The new methodologies to identify patterns in stock prices have resulted in a considerable advance in the research of technical and fundamental analysis, portfolio theory and, forecasting models. However, buying and selling stocks in the market remains an activity that involves high uncertainty.

Nowadays is essential for investors and stockholders to get better techniques to find advanced information on the stock price to obtain the highest returns. Therefore, to identify the patterns and movements of stock prices, academics of the fuzzy theory have been generated different hypotheses and methodologies that have demonstrated their capacity to forecast high uncertainty variables.

Fuzzy time series are fuzzy relational equations and approximate reasoning (Song and Chissom, 1993a). The authors based the model on the concept of uncertainty and imprecise knowledge contained in time series data. As a noneconomic application, Song and Chissom (1993b) presented the definition of fuzzy time series as an inherently dynamic process in which the observations are linguistic values.

Tseng et al. (2001) mixed the ARIMA time series model and the fuzzy regression model to develop a new methodology called the Fuzzy-ARIMA model. They applied it to forecast the exchange rate of New Taiwan dollars (NTD) to the United States of America dollars (USD). The main contribution of this paper is to provide decision-makers with the best and worst possible situations.

Relevant work on the topic is the Pal et al. (2018) paper; they forecasted diverse sets of time series (some non-financial). They used neural network analysis to modify the adjustment of the weights under fuzzy models of type 2 . Their results showed that the model directs to recognize the uncertainty of different time series. Similar Works are (Yu \& Huarng, 2010; Xiao, 2017); (Han, Zhong, \& Han., 2018); (Egrioglu, Aladag, \& Yolcu, 2013); (Souza \& Torres, 2018), (Medina-Reyes, CastroPérez, Cabrera-Llanos, \& Cruz-Aké, 2020).

The importance of the previously mentioned research is that fuzzy methodology better predicts the behavior of stock prices and other financial industry variables. Therefore, this research expects to incorporate fuzzy systems to improve the learning of neural networks and combining this one with portfolio theory to generate portfolios with the highest returns.

On the other hand, portfolio theory provides the basis for establishing better management of the risks inherent in financial assets, based on the use of the statistical properties of the time series of stock prices (Markowitz, 1991).

Portfolio theory has been the main theoretical framework for the development of different and numerous investigations. A way of researching is the combination of fuzzy theory, neural networks, and portfolio theory.

The measuring of the risk-return on investment portfolios by fuzzy models are the fundamental issues analyzed. The behavior of stock prices has a membership function that recognized the portfolio that guarantees returns to investors with the minimum risk (Huang, 2008), (Calvo, Ivorra, \& Liern, 2014), (Kar, Kar, Guo, Li, \& Majumder, 2018), (Ramli \& Jaaman, 2019) and (Shiraz, Tavana, \& Fukuyama, 2020). 
The risk management portfolio problem has been an important area of analysis. An alternative to minimize risk is to model stock price volatility through neural networks to find a more efficient investment distribution and apply the portfolio theory to find the highest return portfolios (Chen, Zhong, \& Chen, 2020), (Zhang, et al., 2020), (Gong, Yu, Min, \& Ge, 2021), (Galankashi, Rafiei, \& Ghezelbash, 2020), Guo, et al., 2020), (Li, \& Deng, (2020) and (Khanjani, Tavana, \& Fukuyama, 2020).

Raei (2006) combined Markowitz's model and showed that portfolios made by the methodology generated a higher return than the conventional portfolio theory. The application of neural networks to identify better management of a stock portfolio, looking for better profitability, has been demonstrated to be a method that achieves a better distribution of weights of the assets in a portfolio, ensuring a higher return compared to other methodologies (Fernández \& Gómez, 2007), (Ko \& Lin, 2008), (Iqbal, Sandhu, Amin, \& Manzoor, 2019) and (Yu, Deng, Chen, \& Cheng, 2020).

The problem analyzed in this research is that the traditional portfolio selection models still do not guarantee the best return or the lowest risk. The problem is that there are no models that show $100 \%$ efficiency in the objective of maximizing the return on investors' resources, government investments, workers' savings, investment trusts, and other investment funds.

The object of the present research is to compare the returns of the portfolios developed by the proposed methodology called Fuzzy Portfolio Selection with Sugeno Type Fuzzy Neural Network against Markowitz's portfolio theory and the growth of the Mexican stock market; to identify the best investment model. For this purpose, we used ten stock time series in daily format from January 2, 2015, to May 15, 2020, to get the portfolios and assuming investment periods of a week in the period May 15 to June 12, 2020. The suggested methodology recognized the behavior of each share, generates better risk management, and higher returns in comparison with the traditional technique.

The hypothesizes is that the proposed technique generates higher returns and shows better risk management than conventional portfolio selection methods. The portfolio selection methodology based on the fuzzy theory has greater efficiency in the investing process.

We organize the research as follows: In the second section, we examined the Autoregressive Nonlinear Fuzzy Neural Network; in the third section, we analyzed the Fuzzy Portfolio Selection with Suggestive Type Fuzzy Neural Network; then, we obtained the Fuzzy Portfolio Selection of the Mexican Actions; and finally, we discuss the conclusions and recommendations.

\section{Hybrid Fuzzy Nonlinear Autoregressive Neural Network: Fuzzy Triangular NARNET, Fuzzy Trapezoidal NARNET, and Fuzzy Pentagonal NARNET}

This section shows the theoretical structure of the Fuzzy Autoregressive Neural Network for three cases. First, the neural network with a triangular membership function and its capacity to generate volatility forecasts in financial variables. Next, we studied the neuronal network with trapezoidal membership function in conjunction with its theoretical framework to generate estimations of high volatility time series, as financial variables. Finally, we develop the pentagonal membership function with the models from Medina-Reyes, Castro-Pérez, Cabrera-Llanos, and Cruz-Áke (2020). 


\subsection{Fuzzy Triangular NARNET}

The Fuzzy Triangular Autoregressive Neural Network is a Sugeno-type first-order model. This method has three IF-THEN rules in the input layer, defined as:

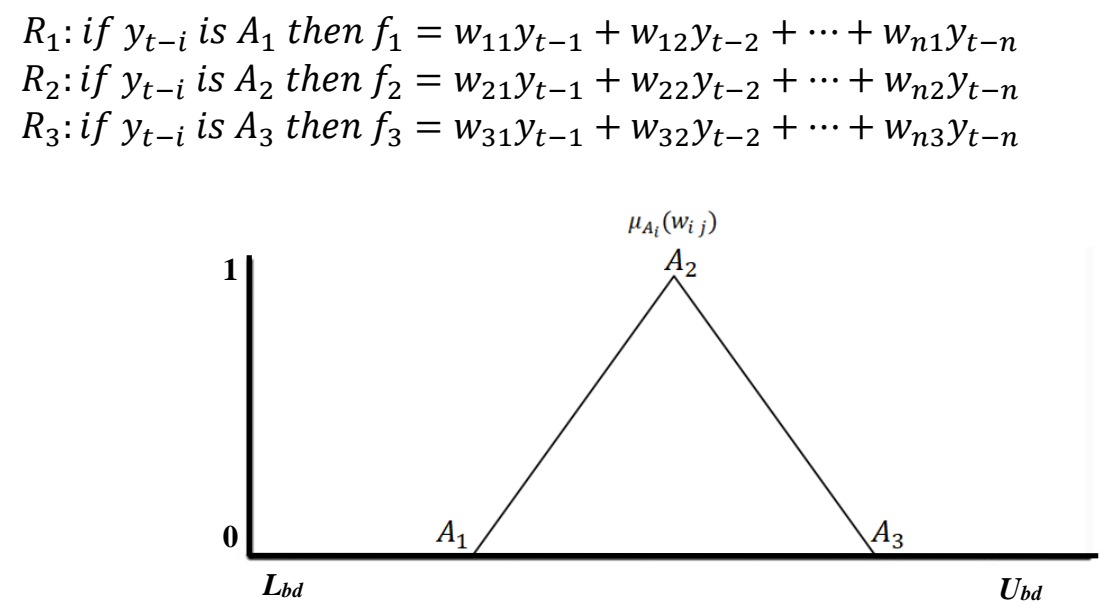

Figure 1. Triangular membership function

Source: Obtained from Medina-Reyes et al. (2020).

where $R_{1}, R_{2}$ and $R_{3}$ are the IF-THEN rules in the input layer; $A_{1}, A_{2}$ and $A_{3}$ are the fuzzy subset of fuzzy time series, and each associated perceptron are $f_{1}, f_{2}$, and $f_{3}$ with their respective $w$ weights.

Figure 1 shows the membership function $\mu_{A_{i}}\left(w_{i j}\right)$ of the fuzzy time series; and each IF-THEN rule $R$ corresponds to every fuzzy subset $A$. In this case, the fuzzy subsets are levels of volatility, and the IF-THEN rules are the fuzzy learning functions of the neural network in the input layer.

The IF-THEN rules in the hidden layer are:

$$
\begin{aligned}
& R_{1} \text { : if } y_{t-i} \text { is } A_{1} \text { then } f_{l 1}=w_{k 1} f_{1}+w_{k 2} f_{1} \\
& R_{2}: \text { if } y_{t-i} \text { is } A_{2} \text { then } f_{l 2}=w_{m 1} f_{2}+w_{m 2} f_{2} \\
& R_{3}: \text { if } y_{t-i} \text { is } A_{3} \text { then } f_{l 3}=w_{m 1} f_{3}+w_{m 2} f_{3}
\end{aligned}
$$

where $R_{1}, R_{2}$ and $R_{3}$ are the IF-THEN rules in the hidden layer; $A_{1}, A_{2}$ and $A_{3}$ are the fuzzy subset of fuzzy time series, and each associated perceptron are $f_{l 1}, f_{l 2}$, and $f_{l 3}$ with their respective $w$ weights.

The advantage of this method compared to the traditional Autoregressive Neural Network is that the proposed model learns from the volatility in three ways:

a) High volatility caused by good news,

b) high volatility generated by bad news and,

c) low volatility.

For instance, this method generates a forecast of the membership function of the fuzzy volatility and the non-fuzzy volatility in comparison with the traditional model that only makes forecasts on the non-fuzzy volatility. 


\subsection{Fuzzy Trapezoidal NARNET}

The second method is the Fuzzy Trapezoidal Membership Function on the Autoregressive Neural Network. This network is a fuzzy first-order model of the Sugeno type, and its IF-THEN rules in the input layer are determined as follows:

$$
\begin{aligned}
& R_{1} \text { : if } y_{t-i} \text { is } A_{1} \text { then } f_{1}=w_{11} y_{t-1}+w_{12} y_{t-2}+\cdots+w_{1 n} y_{t-n}, \\
& R_{2}: \text { if } y_{t-i} \text { is } A_{2} \text { then } f_{2}=w_{21} y_{t-1}+w_{22} y_{t-2}+\cdots+w_{2 n} y_{t-n}, \\
& R_{3}: \text { if } y_{t-i} \text { is } A_{3} \text { then } f_{3}=w_{31} y_{t-1}+w_{32} y_{t-2}+\cdots+w_{3 n} y_{t-n}, \\
& R_{4}: \text { if } y_{t-i} \text { is } A_{4} \text { then } f_{4}=w_{41} y_{t-1}+w_{42} y_{t-2}+\cdots+w_{4 n} y_{t-n}
\end{aligned}
$$

where $R_{1}, R_{2}, R_{3}$ and $R_{4}$ are the IF-THEN rules in the input layer; $A_{1}, A_{2}, A_{3}$ and $A_{4}$ are the fuzzy subset of fuzzy time series, and each associated perceptron are $f_{1}, f_{2}, f_{3}$ and $f_{4}$ with their respective $w$ weights.

Figure 2 shows the membership function $\mu_{A_{i}}\left(w_{i j}\right)$ of the fuzzy time series; and each IF-THEN rule $R$ corresponds to every fuzzy subset $A$. In this case, the fuzzy subsets are levels of volatility, and the IF-THEN rules are the fuzzy learning functions of the neural network in the input layer.

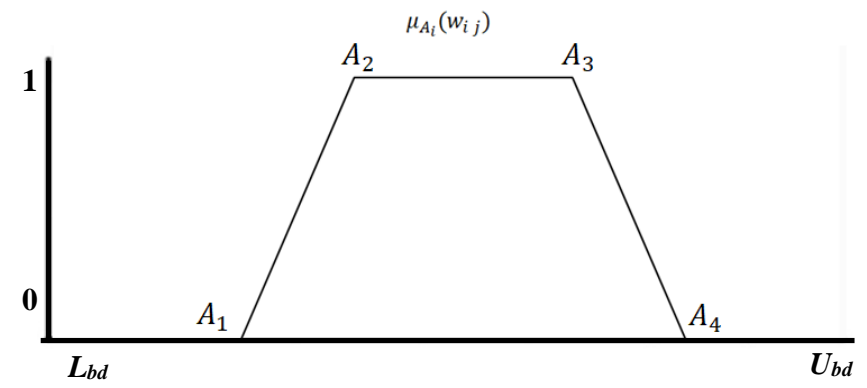

Figure 2. Trapezoidal Membership function

Source: Obtained from Medina-Reyes et al. (2020).

In this case, $\mu_{A_{i}}\left(w_{i j}\right)$ is the trapezoidal fuzzy subset of each function, $f$, that is the fuzzy perceptron with their respective, $w$, weights in the hidden layer of the neural network. Now the IFTHEN rules in the hidden layer are:

$$
\begin{aligned}
& R_{1}: \text { if } y_{t-i} \text { is } A_{1} \text { then } f_{l 1}=w_{k 1} f_{1}+w_{k 2} f_{1} \\
& R_{2}: \text { if } y_{t-i} \text { is } A_{2} \text { then } f_{l 2}=w_{m 1} f_{2}+w_{m 2} f_{2,} \\
& R_{3}: \text { if } y_{t-i} \text { is } A_{3} \text { then } f_{l 3}=w_{m 1} f_{3}+w_{m 2} f_{3}, \\
& R_{4}: \text { if } y_{t-i} \text { is } A_{4} \text { then } f_{l 4}=w_{m 1} f_{4}+w_{m 2} f_{4} .
\end{aligned}
$$

The advantage of this method compared to the traditional Autoregressive Neural Network is that the proposed model learns from the volatility in four ways:

a) High volatility caused by good news,

b) High volatility generated by bad news and,

c) Low high volatility

d) High low volatility. 
For instance, this method generates a forecast of the membership function of the fuzzy volatility and the non-fuzzy volatility in comparison with the traditional model that only makes forecasts on the non-fuzzy volatility.

\subsection{Fuzzy Pentagonal NARNET}

The third method is the proposed Fuzzy Pentagonal Membership Function on the Autoregressive Neural Network. This network is a fuzzy first-order model of the Sugeno type, and its IF-THEN rules in the input layer are determined as follows:

$$
\begin{aligned}
& R_{1} \text { : if } y_{t-i} \text { is } A_{1} \text { then } f_{1}=w_{11} y_{t-1}+w_{12} y_{t-2}+\cdots+w_{1 n} y_{t-n}, \\
& R_{2}: \text { if } y_{t-i} \text { is } A_{2} \text { then } f_{2}=w_{21} y_{t-1}+w_{22} y_{t-2}+\cdots+w_{2 n} y_{t-n}, \\
& R_{3}: \text { if } y_{t-i} \text { is } A_{3} \text { then } f_{3}=w_{31} y_{t-1}+w_{32} y_{t-2}+\cdots+w_{3 n} y_{t-n} \\
& R_{4}: \text { if } y_{t-i} \text { is } A_{4} \text { then } f_{4}=w_{41} y_{t-1}+w_{42} y_{t-2}+\cdots+w_{4 n} y_{t-n} \\
& R_{5}: \text { if } y_{t-i} \text { is } A_{5} \text { then } f_{5}=w_{51} y_{t-1}+w_{52} y_{t-2}+\cdots+w_{5 n} y_{t-n}
\end{aligned}
$$

where $R_{1}, R_{2}, R_{3}, R_{4}$ and $R_{5}$ are the IF-THEN rules in the input layer; $A_{1}, A_{2}, A_{3}, A_{4}$ and $A_{5}$ are the fuzzy subset of fuzzy time series, and each associated perceptron are $f_{1}, f_{2}, f_{3}, f_{4}$ and $f_{5}$ with their respective $w$ weights.

Figure 3 shows the membership function $\mu_{A_{i}}\left(w_{i j}\right)$ of the fuzzy time series; and each IF-THEN rule $R$ corresponds to every fuzzy subset $A$. In this case, the fuzzy subsets are levels of volatility, and the IF-THEN rules are the fuzzy learning functions of the neural network in the input layer.

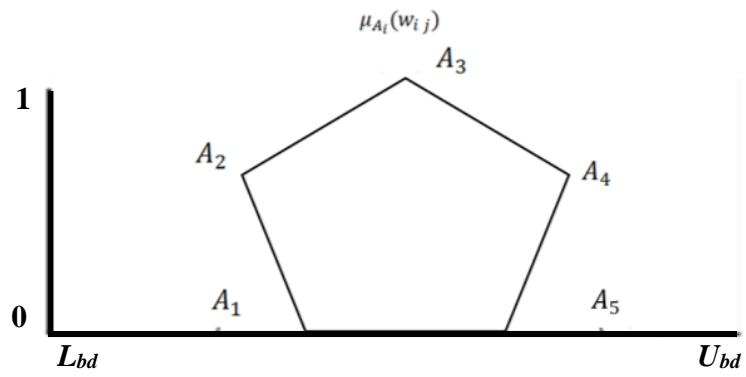

Figure 3. Pentagonal Membership function Source: Own creation in MatLab.

In this case, $A$ is the pentagonal fuzzy subset of each function, $f$, that is the fuzzy perceptron with their respective, $w$, weights in the hidden layer of the neural network. Now the "If-Then rules" in the hidden layer are:

$$
\begin{aligned}
& R_{1}: \text { if } y_{t-i} \text { is } A_{1} \text { then } f_{l 1}=w_{k 1} f_{1}+w_{k 2} f_{1}, \\
& R_{2}: \text { if } y_{t-i} \text { is } A_{2} \text { then } f_{l 2}=w_{m 1} f_{2}+w_{m 2} f_{2,} \\
& R_{3}: \text { if } y_{t-i} \text { is } A_{3} \text { then } f_{l 3}=w_{m 1} f_{3}+w_{m 2} f_{3}, \\
& R_{4}: \text { if } y_{t-i} \text { is } A_{4} \text { then } f_{l 4}=w_{m 1} f_{4}+w_{m 2} f_{4} \\
& R_{5}: \text { if } y_{t-i} \text { is } A_{5} \text { then } f_{l 5}=w_{m 1} f_{5}+w_{m 2} f_{5}
\end{aligned}
$$


The advantage of this method compared to the traditional Autoregressive Neural Network is that the proposed model learns from the volatility in four ways:

a) High volatility caused by good news,

b) High volatility generated by bad news and,

c) Low Low volatility

d) Low high volatility

e) High low volatility.

For instance, this method generates a forecast of the membership function of the fuzzy volatility and the non-fuzzy volatility in comparison with the traditional model that only makes forecasts on the non-fuzzy volatility.

2.4 Neural network structure

In the first phase, each node must be categorized into the respective membership function of the fuzzy subset to which it belongs; this means that $y_{t}$ is the variable that feeds each node, $i$, and $A_{i}$ represents the fuzzy subset as a linguistic value in the fuzzy time series.

$$
y_{t}=A_{i}
$$

Where $A_{i}$ is the fuzzy set of $y_{t}$. Moreover, it expresses the fuzzy time series. In this specific case, the membership function may be a triangular, trapezoidal, or pentagonal type. To improve the learning function, we soften the information following the procedure of García et al. (2002):

$$
z_{t-1}=\frac{y_{t-1}-\mu\left(y_{t-1}+y_{t-2}+\cdots+y_{t-n}\right)}{\sigma\left(y_{t-1}+y_{t-2}+\cdots+y_{t-n}\right)}
$$

In the second phase, the IF-THEN rules (1), (3), and (5) represent the nodes in the first layer. That is, the nodes are the multiplication of the different signals and whose sum represents the output.

$$
f=w_{1} z_{t-1}+w_{2} z_{t-2}+\cdots+w_{n} z_{t-n}
$$

In the third phase, the outputs of the previous step are the new signals that activate the sigmoid function of the hidden layer, which is defined by the IF-THEN rules (2), (4), and (6).

$$
f_{s}(f)=\frac{1}{1+e^{-f}}
$$

The last equation is a sigmoidal activation function. So, the next equation denotes the hidden step.

$$
f_{l}=w_{1} f_{s}+w_{2} f_{s}
$$

We want to stress that in the last single node, we perform the sum of all the output signals of the previous phases. The output variable, $y_{t}$, is: 


$$
\widehat{\mathrm{y}_{\mathrm{t}}}=\mathrm{f}_{\mathrm{l}} * \sigma\left(\mathrm{y}_{\mathrm{t}-1}+\mathrm{y}_{\mathrm{t}-2}+\cdots+\mathrm{y}_{\mathrm{t}-\mathrm{n}}\right)+\mu\left(\mathrm{y}_{\mathrm{t}-1}+\mathrm{y}_{\mathrm{t}-2}+\cdots+\mathrm{y}_{\mathrm{t}-\mathrm{n}}\right)
$$

where $\widehat{y}_{t}$ is the forecast of $y_{t}, \sigma$ is the variance of the past values, and $\mu$ represents the mean of the lags. The Absolute Mean Deviation is the error function, such as:

$$
\epsilon=\frac{E\left|y_{t}-\hat{y}_{t}\right|}{n} \text {. }
$$

The IF-THEN rules give the basis for the learning algorithm of the adaptive network based on fuzzy inference. Also, it is interesting to note that a linear combination of the model parameters can express the observations; this is:

$$
f=\overline{w_{1}}\left(p_{1} y_{t}+r_{1}\right)+\overline{w_{2}}\left(p_{2} y_{t}+r_{2}\right)
$$

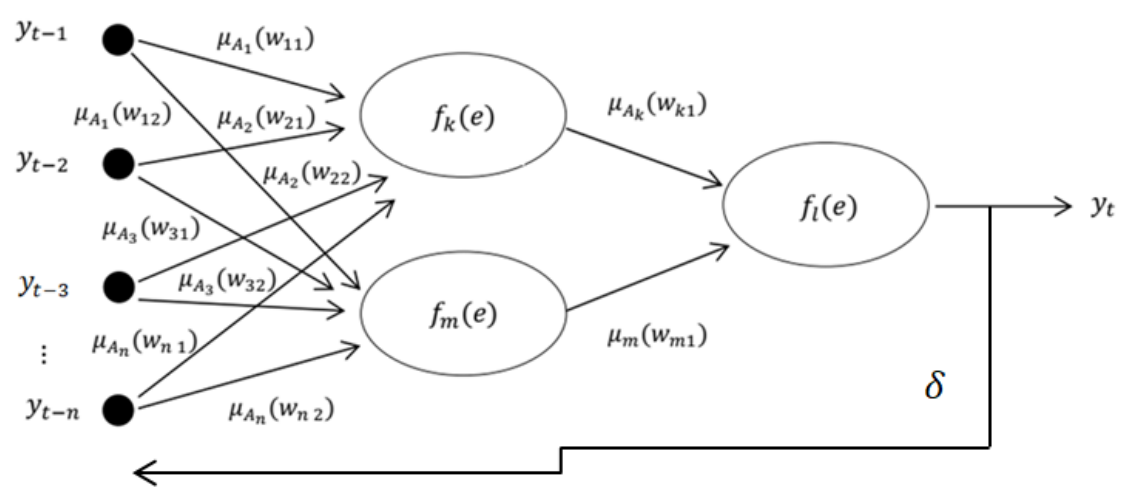

Figure 4. Hybrid Fuzzy Nonlinear Autoregressive Neural Network Source: Obtained from Medina-Reyes et al. (2020).

The main advantage of the proposed neural network compared to the Autoregressive Neural Network is that we can decide the lags and the classification of the membership function. In other words, our method allows defining how the neural network learns by controlling the weights of past patterns and the membership function of the Time Series.

\section{Fuzzy Portfolio Selection with Sugeno Type Fuzzy Neural Network}

The portfolio theory assumes that risk management in investment requires a historical analysis of stock prices. In other terms, the risk and expected return of an asset is correlating to past values of the share. Therefore, the maximum expected return of Markowitz's portfolio is the one generated by the stocks in the past, indicating that the average behavior, size, and price variability of the selected shares, provide the different portfolio distributions for several levels of returns. 
So far, portfolio analysis has concentrated on two modalities, the historical assessment with the mean-variance theorem and the problem of how to obtain the appropriate parameters that will take the weights of each asset in the portfolio.

The proposed methodology develops a new structure; to build the election of the expected return of the financial assets in the portfolio, but the algorithm of the choice of weights that uses the theory of portfolios is maintained.

Assumption one: The historical behavior of stock prices is a fuzzy neural network (Fuzzy triangular, fuzzy trapezoidal, and fuzzy pentagonal NARNET). Then, the volatility is captured by a neural network structure that incorporates market uncertainty through a membership function.

We propose to build the model through a fuzzy neural network; the historical profitability is the forecast of the stock, and the volatility is the prediction error. Put it another way; the proposed portfolio does not utilize the return either the volatility of the stock prices as a source for risk management.

Assumption two: The expected return $r_{i}$ on an asset $i$ is the forecast return of the fuzzy neural networks $r_{F F N N i}$.

$$
r_{i}=r_{F F N N i}
$$

This assumption refers to the fact that the expected return on each asset used in the portfolio will be the forecast provided by the fuzzy neural network applied for its analysis. Then, the expected profitability of the fuzzy portfolio will be as follows:

$$
R_{f p}=\sum_{i=1}^{N} x_{F F N N i} * r_{F F N N i}
$$

where $R_{f p}$ is the expected return of the fuzzy neural network portfolio, $x_{F F N N i}$ is the vector of weights, and $r_{F F N N i}$ refers to the expected return of each asset. So, the expected return is the forecast of fuzzy neural networks, and the risk source is the forecast error.

$$
\sigma_{f p}=\sum_{i=1}^{N} M A D_{i}{ }^{*} x_{F F N N i}
$$

Where $\sigma_{f p}$ is the risk of the fuzzy portfolio, and $M A D_{i}$ is the mean absolute deviation that represents the forecast error of the asset $i$. Then, the sum of the mistakes of each asset multiplied by its respective weights in the portfolio gives us the risk of investing with this model.

The portfolio diversification model seeks to find the portfolio with the expected risk-return combinations that comply with the (16) and (17) conditions of the asset price, which is subject to the budgetary restriction or restriction of the allocated investment amount.

$$
\begin{gathered}
\text { Optimize } U\left(R_{f p}, \sigma_{f p}\right) \\
\text { Subject to } \\
\sum_{i=1}^{N} \omega_{i}=1
\end{gathered}
$$


The restriction refers to the total amount you want to invest according to the individual proportions of the assets, and each unit signifies the sum amount invested. If this restriction is higher than one, the investor is investing with higher capital or with debt in the investment portfolio. On the other hand, if this condition is lower than one, the investor is allocating fewer resources than necessary to cover the portfolio. However, if the proportion of financial assets is negative, it means that the investor is in a short position.

Then, the process of the fuzzy neural network portfolio model is the next:

I. Select the assets and sample to be analyzed.

II. Calculate the returns of the historical prices of each share as:

$$
r_{i}=\ln \left(\frac{p_{t}}{p_{t-1}}\right)
$$

III. Model each time series of the last step as a fuzzy neural network. We recommend forecasting the variable through the three models presented in the previous section (fuzzy triangular NARNET, fuzzy trapezoidal NARNET, and fuzzy pentagonal NARNET); and after that may be used the mean of all prediction as (14) more details see (Medina-Reyes et al., 2020).

IV. Obtain the prediction error of the neural networks estimated in the last section. After that, using the average MAD of the three forecasts of each share as (16).

V. Optimize (17) subject to the sum of the weights is equal to one. We suggest optimizing the portfolio for different objective values in the expected returns and prediction errors.

VI. Select the best investment distribution according to the risk aversion of each investor.

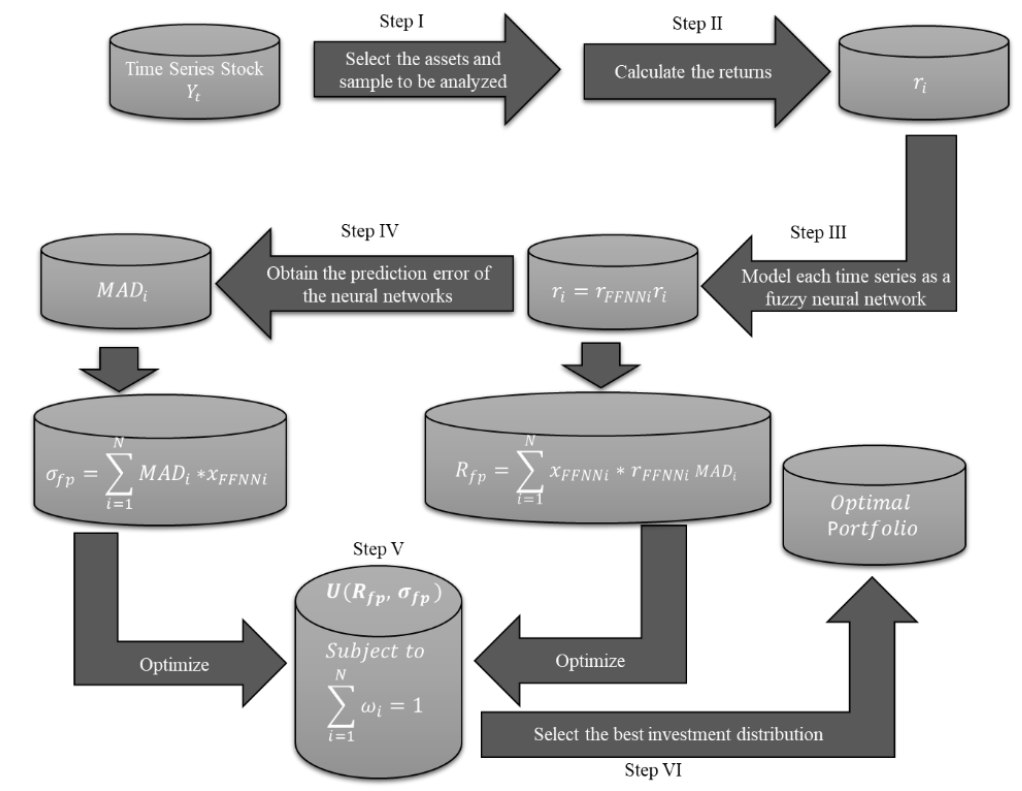

Figure 5. Fuzzy Portfolio Selection with Sugeno Type Fuzzy Neural Network Model Source: Own creation in PowerPoint. 


\section{Mexican Stocks Fuzzy Portfolio Selection}

We structured the fuzzy neural network portfolio selection with ten assets ${ }^{3}$ of the Mexican stock market. The period under review is from January 2, 2015, to May 15, 2020, in a daily format. First, we analyzed the trend component, price volatility, and the main statistical elements of each share. After, the three fuzzy neural networks proposed are applied to learn about the historical behavior of every stock and forecast used in steps III and IV.

The initial assumption is that the assets were bought on Friday and sold the next Friday. Therefore, the investment period is in a week. In other terms, the learning of the network is in a daily format and the investment period is weekly. Furthermore, we do not consider the transaction costs of buying and selling the stocks, so it obtained the gross return.

\subsection{First-week portfolio}

The portfolios correspond to week one was elaborated with the predictions of the fuzzy neuronal networks. Upon carrying out the study, we found that the source of risk (forecast error) does not comply with the criteria of the Markowitz methodology; on the other hand, the greater return implies more risk. Figure 6 has three main components, the expected in white bars, the obtained in blue bars, and the forecast error in the red line.

This research listed the fuzzy portfolios from one to fourteen, where the first one has the lowest value and the last one the highest expected return. Also, the table below shows the values that correspond to each of the components of the portfolios.

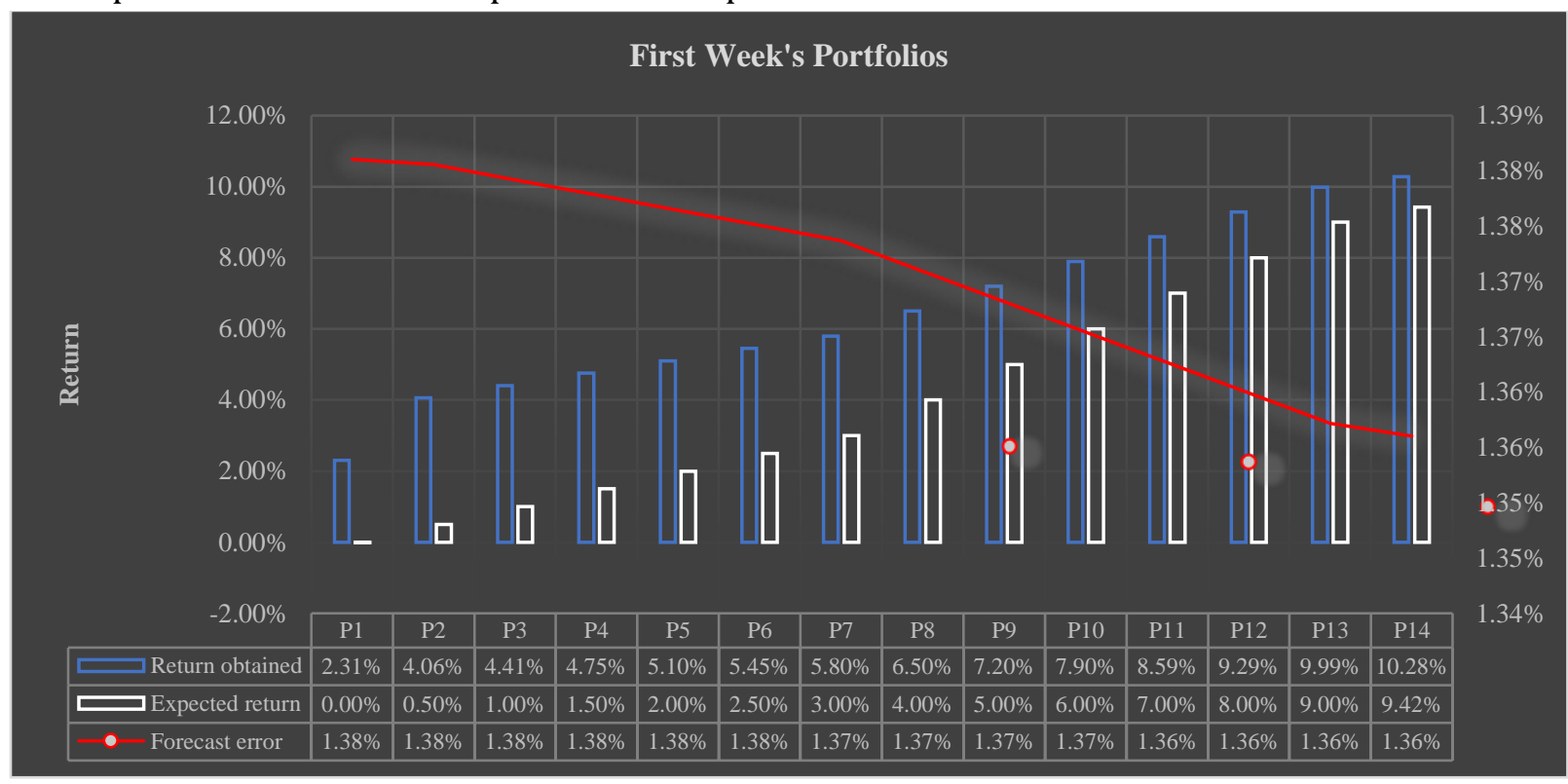

Figure 6. Fuzzy Portfolio Selection with Sugeno Type Fuzzy Neural Network, first week's portfolios Source: Own creation in Excel with data from Yahoo Finances.

3 The shares diagnosed are Alfa, S.A.B. de C.V.; American Movil, S.A.B. de C.V.; Bolsa Mexicana De Valores, S.A.B. de C.V.; Grupo Financiero Banorte, S.A.B de C.V.; Grupo Industrial Maseca, S.A.B., de C.V.; Grupo Financiero Inbursa, S.A.B. de C.V; Grupo Mexico, S.A.B. de C.V.; Megacable Holdings S. A. B. de C.V.; Genomma Lab Internacional, S.A.B. de C.V. 
P14 is the maximum expected benefit and, P1 the return equal to zero. The ratio (maximum return divided by fourteen) is added to the previous target until it finds the maximum expected return portfolio. Finally, solving the problem (17), we obtained the distribution of the weights of each asset.

The results of week one show that all fourteen calculated fuzzy portfolios generated positive returns. The portfolio P1 had an expected return of $0 \%$, and finally, the return obtained is $2.31 \%$. In P14 a return of $9.42 \%$ was expected, and $10.28 \%$ of the profit was obtained, which represents $0.86 \%$ more than expected. These outcomes say that the portfolio selection model provides the investment combinations that guarantee positive returns, and with it, the reduction of the risks faced by investors.

The red line shows that the forecast error decrease. The tendency is the result that fuzzy neural networks estimate better the behavior of the assets predicted. And these forecasts help our model to select higher return portfolios. But this result does not indicate that the risk is lower.

\subsection{Second-week portfolio}

In week two, we have a total of 28 different portfolios, figures 36 and 37 . The portfolios are divided into 14 with and 14 without training. The training refers to the incorporation of the new information into the neural network. In other words, the neural network with training is annexed in the week of May 18 to 22 to generate the forecast of May 29. And in the portfolios without training, the neuronal network learns until May 15, and an out-of-sample forecast is generated until May 29. In this case, we get the weekly profitability and assume the buy day of the asset is on May 22nd, and the sale is on May 29th.

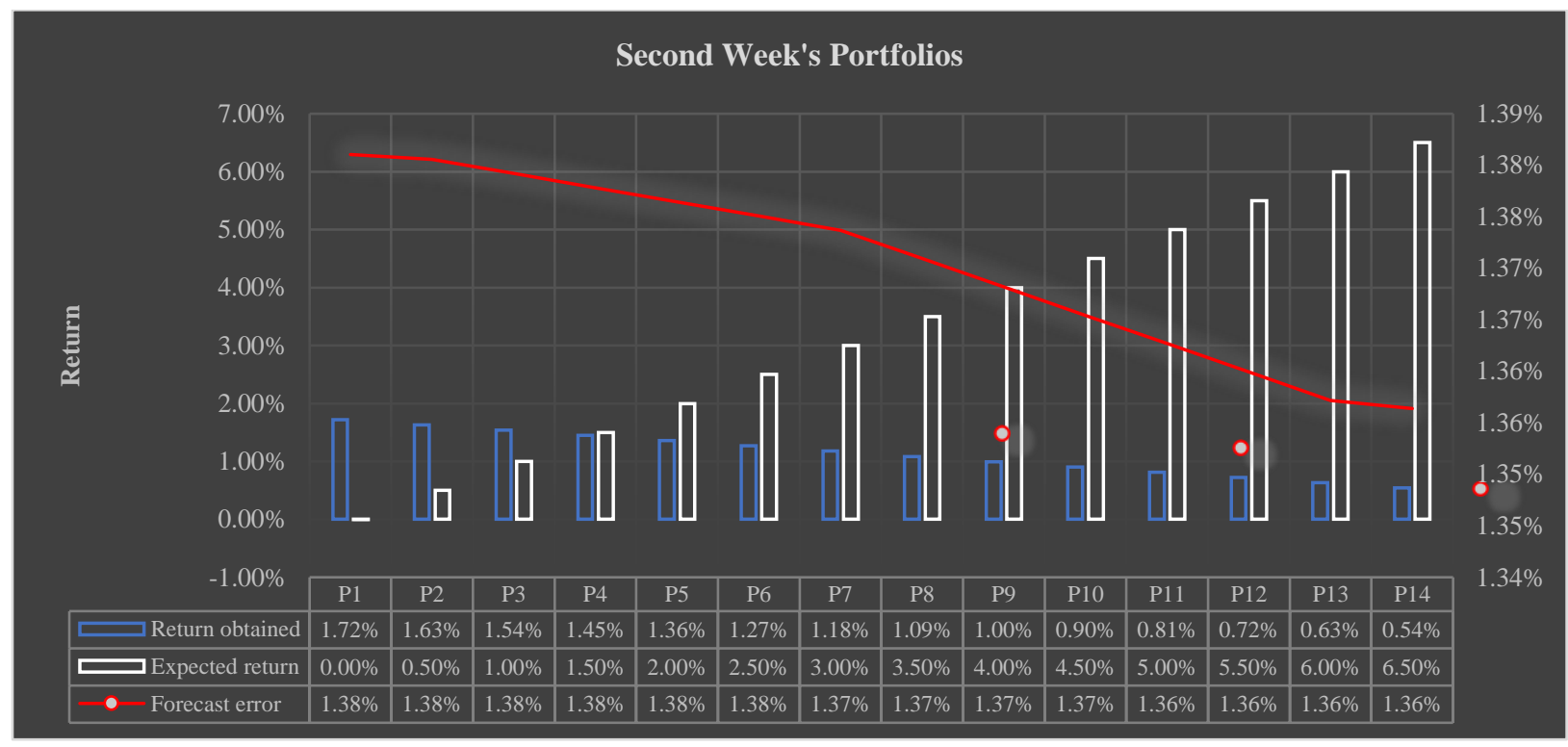

Figure 7. Fuzzy Portfolio Selection with Sugeno Type Fuzzy Neural Network second week without Training Source: Own creation in Excel with data from Yahoo Finances. 
Week two without training, figure 7 shows that all the fuzzy portfolios had positive returns. In portfolio $\mathrm{P} 1$ there is an expected return of $0 \%$, and a weekly return was $1.72 \%$. So, in portfolio P14 there is an expected return of $6.14 \%$, and the profit was $0.54 \%$ which corresponds to $5.92 \%$ less than the estimated value. This result shows that the portfolio selection model provides investment combinations that can guarantee positive returns, and with it, diminish the risks faced by investors. In comparison with week one, we obtained less return.

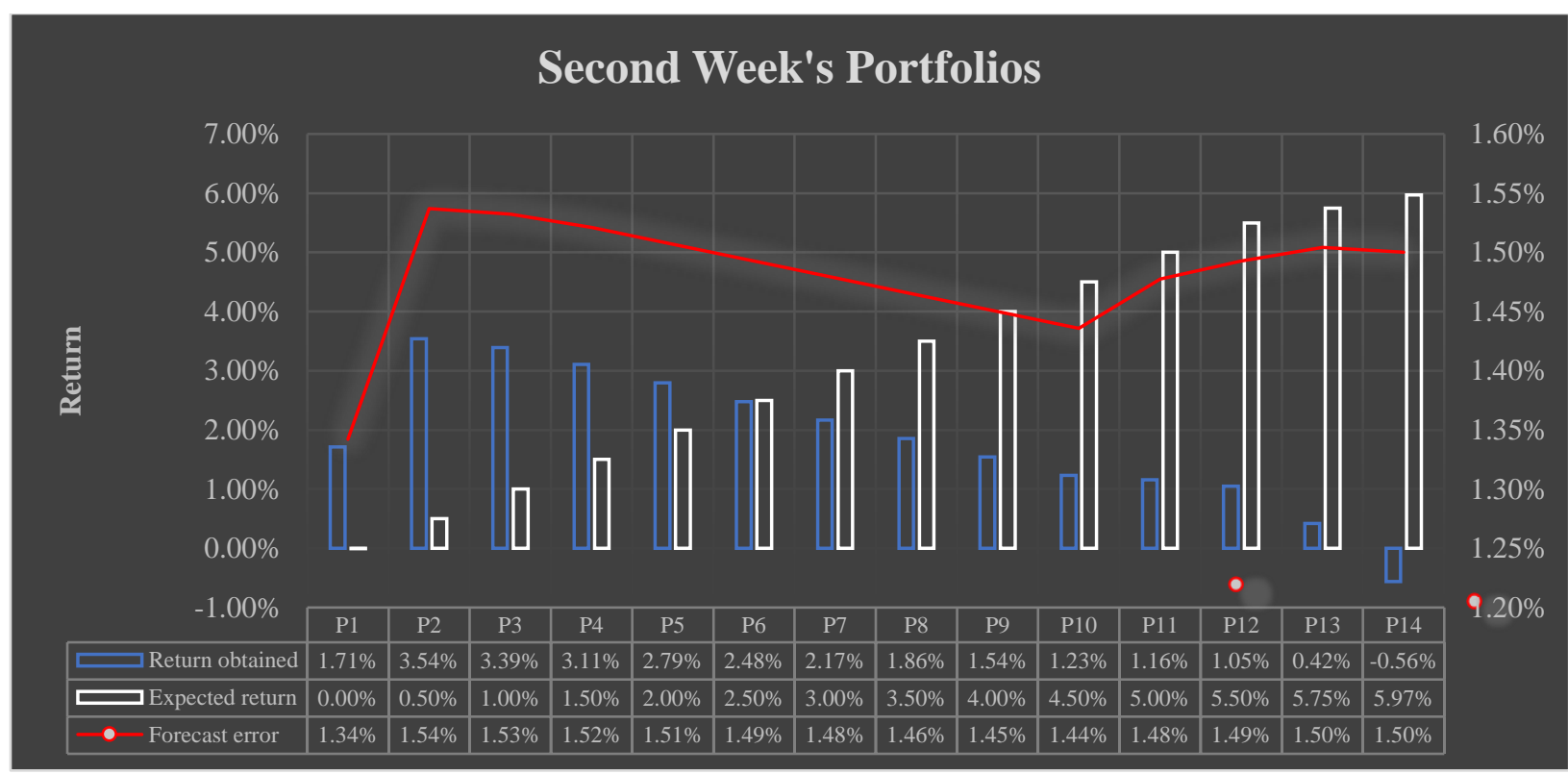

Figure 8. Fuzzy Portfolio Selection with Sugeno Type Fuzzy Neural Network second week with Training

Source: Own creation in Excel with data from Yahoo Finances.

The condition of the neural network with training refers to that the synaptic weights are updated and considers whole information up to the moment of investment. In other terms, the May 29th forecast is calculated with information updated to May 22nd, 2020, this allows to generate different portfolio selections.

Figure 8 shows that the calculated fuzzy portfolios generated positive returns. In P1 there is a return of $0 \%$, and a weekly return of $1.71 \%$ observed. In P14 there is a return of $5.97 \%$ and $-0.56 \%$ of real profit, representing $-6.52 \%$ less than expected. This outcome shows that the portfolio selection model provides investment combinations that can guarantee positive returns in all investment cases, diminishing the risks faced by investors.

In week two the portfolios with training are in general the ones that indicate higher benefits. Being P2 and P3 in figure 8, those that provided the highest weekly return with 3.54\% and 3.39\%. 


\subsection{Third-week portfolio}

Week three corresponds to the buying of the assets on May 29 and the selling of the portfolio on June 5. In week three there is a return behavior of the assets positive, the stocks have positive results, the conditions of the stock market presented increases in the prices.

Figure 9 shows the results of the third week without training, the fourteen fuzzy portfolios generated positive returns. In P1 the expected return is $0 \%$, and a weekly return was $10.85 \%$. In P14 a return of $0.74 \%$ in the portfolio, and it found a benefit of $3.75 \%$, which represents $3.01 \%$ more than expected. Therefore, the portfolio selection model provides investment combinations that can guarantee positive returns and thus manages to reduce the risks faced by investors.

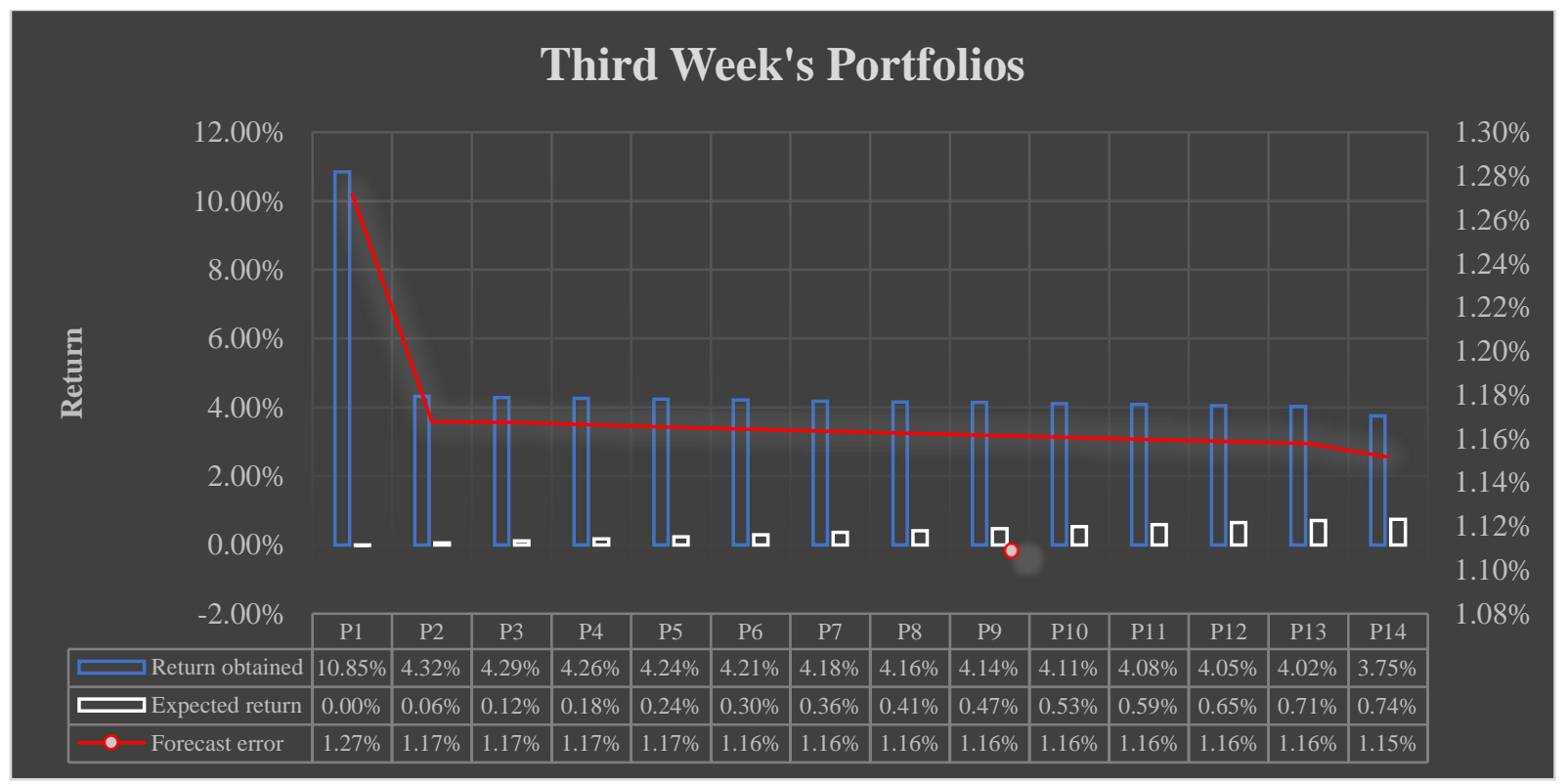

Figure 9. Fuzzy Portfolio Selection with Sugeno Type Fuzzy Neural Network third week without Training

Source: Own creation in Excel with data from Yahoo Finances.

Figure 10 shows that the fuzzy portfolios generated positive returns. In P1 a return of $0 \%$ was expected and a weekly return of $5.74 \%$ was finally observed. In P14 a return of $0.91 \%$ was expected and $3.78 \%$ of the profit was obtained, representing $2.77 \%$ more than expected. 


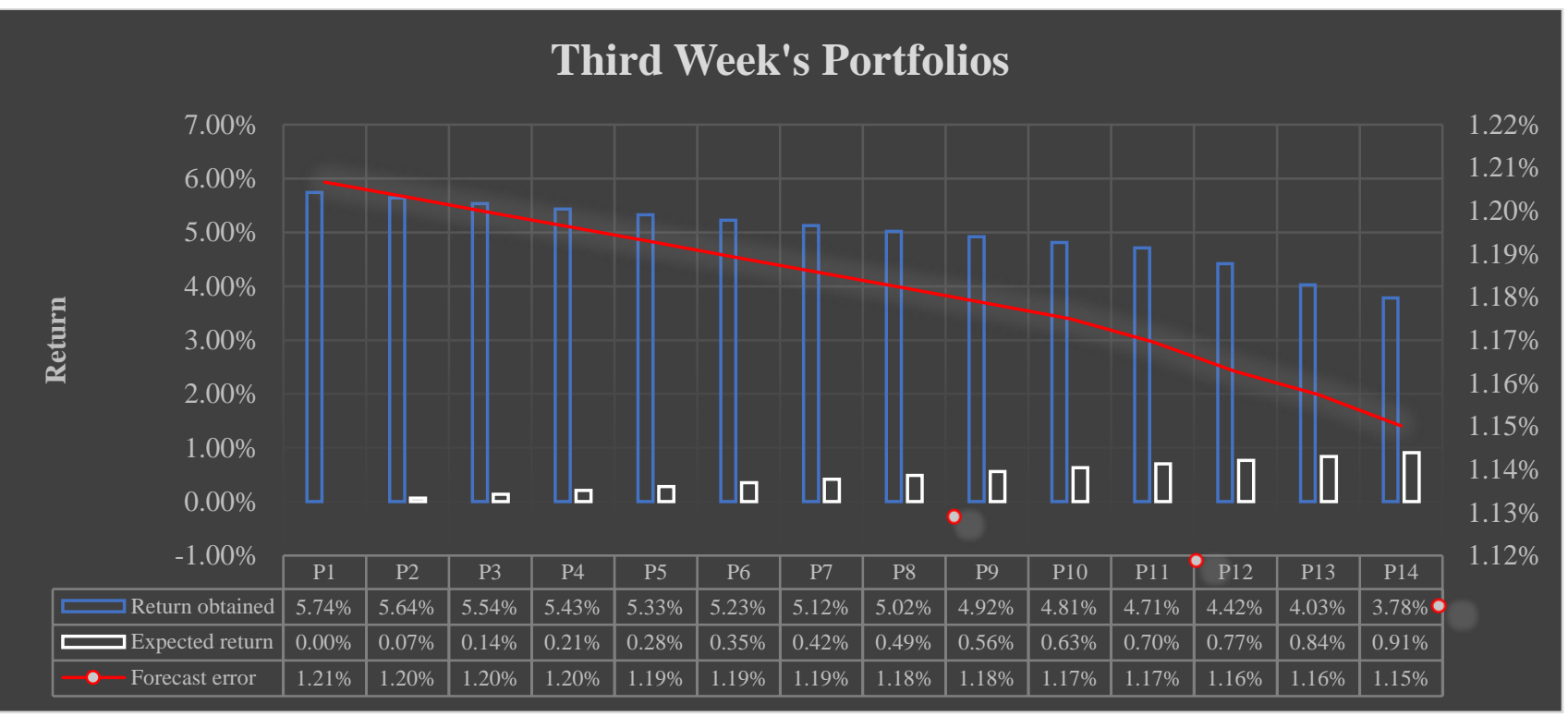

Figure 10. Fuzzy Portfolio Selection with Sugeno Type Fuzzy Neural Network third week with Training

Source: Own creation in Excel with data from Yahoo Finances.

In week three on average the portfolios of neural networks without training guarantee greater return, however, the portfolio with the highest return is P1 in Figure 9 with a 10.85\% gain.

\subsection{Fourth-week portfolio}

Week four corresponds to the buying of the assets on June 5, and the selling of the portfolio on June 12. In the fourth week, the general behavior of financial assets in the Mexican stock market was negative, at the end of the week, the IPC had a weekly fall of $3.31 \%$. This decrease is reflected in the investment portfolios developed with our method.

Figure 11 depicts that twelve fuzzy portfolios generated negative returns. In P1 a return of $0 \%$ was expected, and a weekly return of $0.80 \%$ was finally observed. In P14 a return of $10.67 \%$ was expected, and $-2.68 \%$ of the profit was obtained, representing $12.01 \%$ less than expected. In this case, portfolios with untrained neural networks only P1 and P2 generated positive returns. 


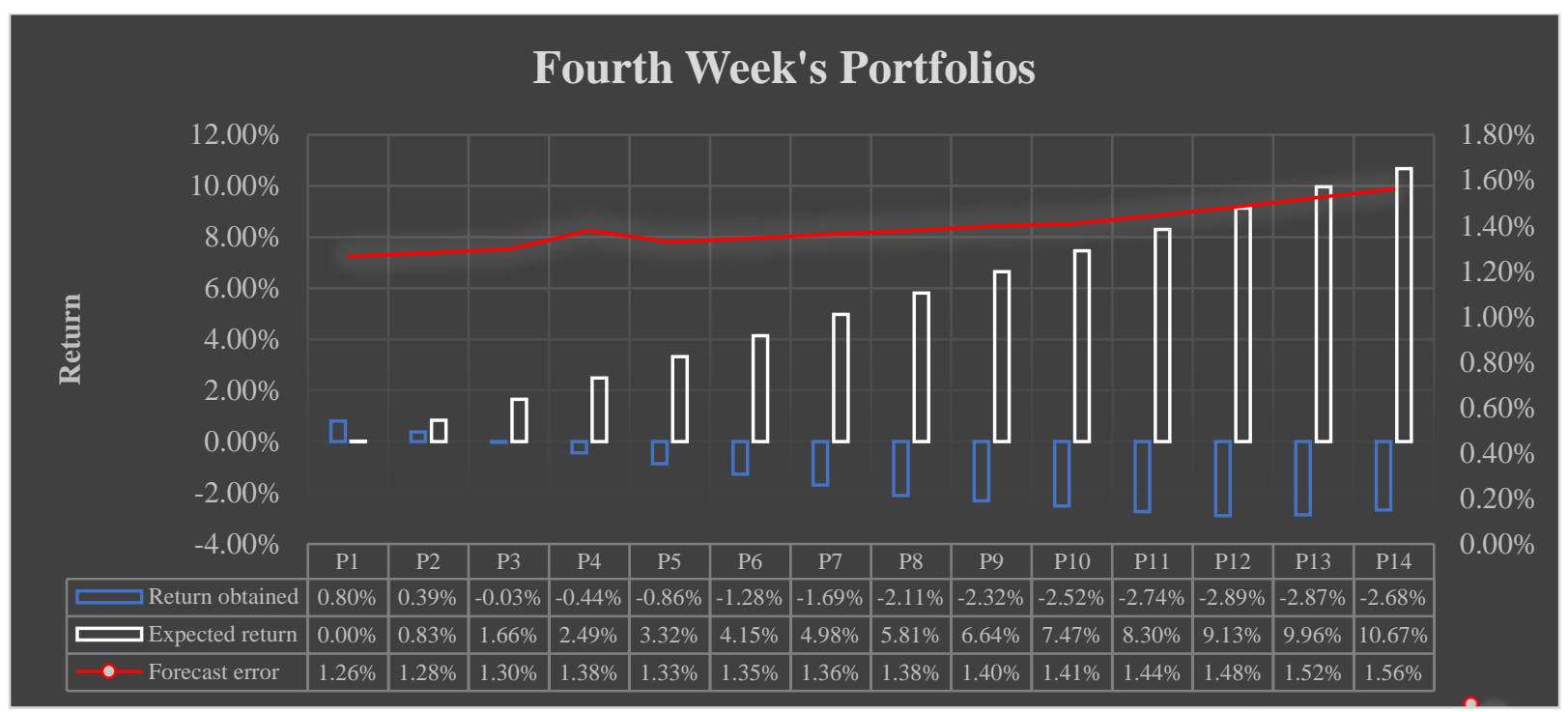

Figure 11. Fuzzy Portfolio Selection with Sugeno Type Fuzzy Neural Network fourth week without Training

Source: Own creation in Excel with data from Yahoo Finances.

Figure 12 shows that all fourteen calculated fuzzy portfolios generated positive returns. In P1 a return of $0 \%$ was expected and a weekly return of $0.22 \%$ was finally observed. In P14 a return of $8.42 \%$ was expected and $-2.68 \%$ of the profit was obtained, representing $10.20 \%$ more than expected. Neural network portfolios with P1-only training generated positive returns. Therefore, the risk in the proposed models is lower than the market, the highest loss that was had with the portfolios was $2.78 \%$ which is $0.53 \%$ lower than the market.

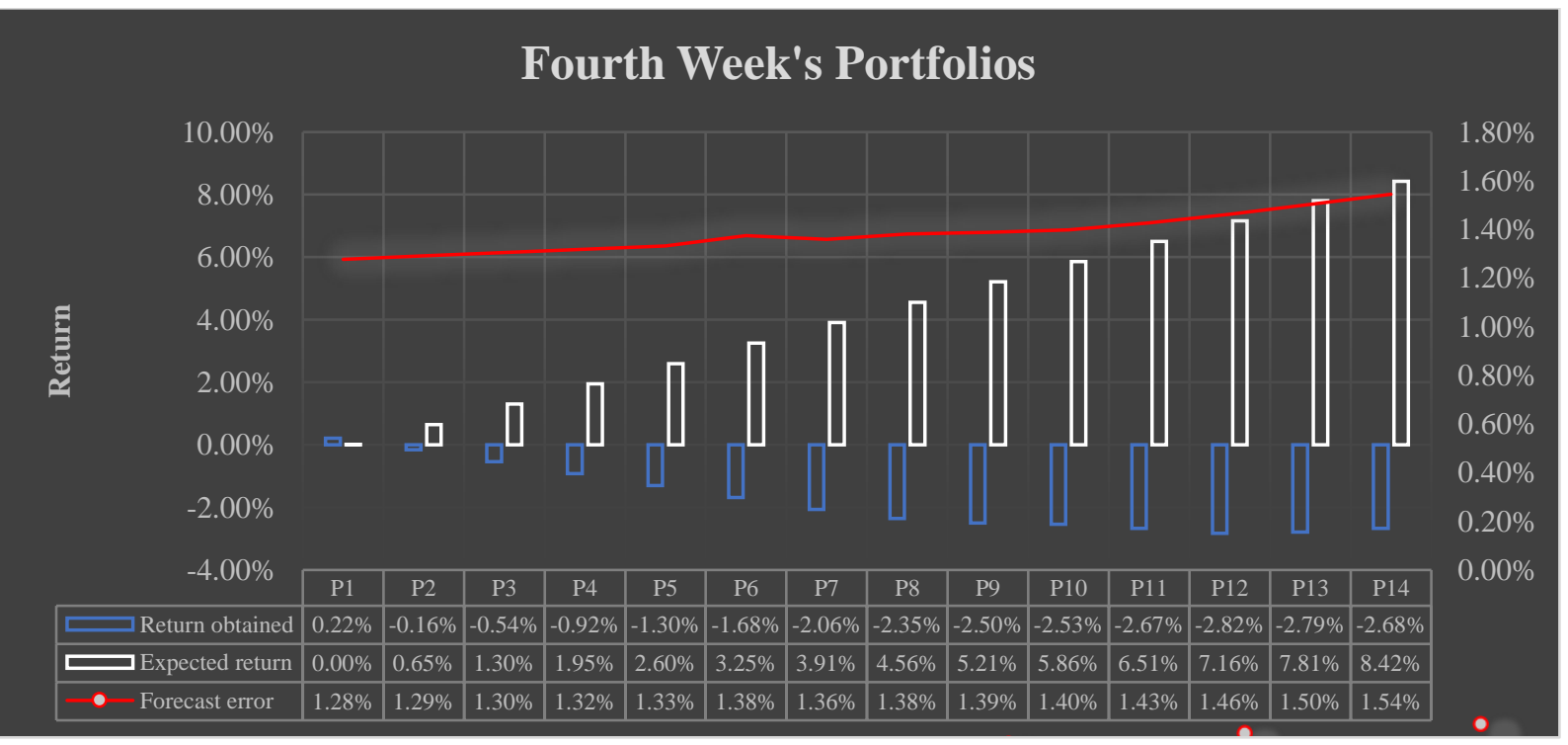

Figure 12. Fuzzy Portfolio Selection with Sugeno Type Fuzzy Neural Network fourth week with Training

Source: Own creation in Excel with data from Yahoo Finances. 


\subsection{Optimum Fuzzy Portfolio}

This section analyses the behavior of investment portfolios over the four weeks studied. Also, a comparison is made of the portfolios identified with the proposed model against the Markowitz methodology and the return on the stock market using the IPC.

The optimal portfolio refers to the distribution of the investment in assets that satisfies an established criterion, this refers to that investment that guarantees the maximum return with the minimum risk, in the Markowitz theory is at the efficient frontier. This type of analysis is done by the combination of risk-return, which provides the best investment consistent with the aversion to the risk of the investor.

The main problem with the proposed method is that it does not allow the development of the efficient frontier since the source of risk does not depend on the behavior of the asset but on the capacity of the model to adjust to the volatility of the time series. Thus, the risk condition presented by the suggested model does not follow the behavior expected in conventional portfolio theory.

So, in this research the optimal model is the one that guarantees the greatest profitability with the least risk. Tables 1 to 4 show the weekly return per portfolio and the final value of each of the investments, comparing the results of the proposed portfolios about three derivatives of the Markowitz theory and the stock market.

Table 1 shows the comparison of the P1 to P7 portfolio against the return of the IPC, the maximum return portfolio, zero return, and the minimum risk portfolio of Markowitz. In week 1, the P7 portfolio generated a return of 5.80\%, which is the one that provided the highest earnings of the compared portfolios. The market only produced $0.26 \%$ of weekly revenues. Also, the 7 portfolios presented at least $0.60 \%$ more returns than those developed with the conventional portfolio theory. Comparing the two lowest risk models, P1 with the Markowitz minimum risk aversion, the proposed methodology generated $1.81 \%$ higher returns than the conventional model.

The second week showed the same behavior as the previous week, portfolios based on fuzzy neural networks generated higher profitability than the benchmarks. In this case, the market had a weekly growth of $0.92 \%$ while the P1 portfolio had weekly profitability of $1.72 \%$, which represents $0.78 \%$ more profit. Whereas the two minimum risk portfolios Markowitz and P1 had a difference of $1.57 \%$ of profitability, is the fuzzy portfolio the one that provided the highest gains. This week the Markowitz portfolios generated the lowest returns. 
Table 1. Comparison of weekly returns on non-training portfolios, part one.

\begin{tabular}{|c|c|c|c|c|c|c|c|c|c|c|c|c|c|}
\hline \multicolumn{2}{|c|}{ DATE } & \multicolumn{8}{|c|}{ TRAINING 2 WEEKS PRIOR } & \multirow{2}{*}{$\begin{array}{c}\text { IPC } \\
\text { RETURN }\end{array}$} & \multicolumn{3}{|c|}{$\begin{array}{c}\text { MARKOWITZ PORTFOLIO } \\
\text { THEORY }\end{array}$} \\
\hline Buy & Sell & $\begin{array}{c}\text { Week } \backslash \\
\text { Portfolio }\end{array}$ & P1 & P2 & P3 & P4 & P5 & P6 & P7 & & $\begin{array}{l}\text { Maximize } \\
\text { return }\end{array}$ & $\begin{array}{c}\text { Zero } \\
\text { return }\end{array}$ & $\begin{array}{l}\text { Minimal } \\
\text { risk }\end{array}$ \\
\hline $\begin{array}{l}15 / 05 / 20 \\
20\end{array}$ & $22 / 05 / 2020$ & 1 & $2.31 \%$ & $4.06 \%$ & $4.41 \%$ & $4.75 \%$ & $5.10 \%$ & $5.45 \%$ & $5.80 \%$ & $0.26 \%$ & $1.70 \%$ & $1.27 \%$ & $0.52 \%$ \\
\hline $\begin{array}{l}22 / 05 / 20 \\
20\end{array}$ & $29 / 05 / 2020$ & 2 & $1.72 \%$ & $1.63 \%$ & $1.54 \%$ & $1.45 \%$ & $1.36 \%$ & $1.27 \%$ & $1.18 \%$ & $0.94 \%$ & $-0.42 \%$ & $-0.49 \%$ & $0.15 \%$ \\
\hline $\begin{array}{l}29 / 05 / 20 \\
20\end{array}$ & $05 / 06 / 2020$ & 3 & $10.85 \%$ & $4.32 \%$ & $4.29 \%$ & $4.26 \%$ & $4.24 \%$ & $4.21 \%$ & $4.18 \%$ & $7.53 \%$ & $2.18 \%$ & $2.50 \%$ & $0.36 \%$ \\
\hline $\begin{array}{l}05 / 06 / 20 \\
20\end{array}$ & $12 / 06 / 2020$ & 4 & $0.80 \%$ & $0.39 \%$ & $-0.03 \%$ & $-0.44 \%$ & $-0.86 \%$ & $-1.28 \%$ & $-1.69 \%$ & $-3.31 \%$ & $0.70 \%$ & $1.90 \%$ & $1.20 \%$ \\
\hline & & $\begin{array}{c}\text { Cumulative } \\
\text { return }\end{array}$ & $15.68 \%$ & $10.40 \%$ & $10.21 \%$ & $10.02 \%$ & $9.84 \%$ & $9.66 \%$ & $9.47 \%$ & $5.42 \%$ & $4.15 \%$ & $5.17 \%$ & $2.22 \%$ \\
\hline
\end{tabular}
Source: Own creation in Excel with data from Yahoo Finances.

Table 2. Comparison of weekly returns on non-training portfolios, part two.

\begin{tabular}{|c|c|c|c|c|c|c|c|c|c|c|c|c|c|}
\hline \multicolumn{2}{|c|}{ DATE } & \multicolumn{8}{|c|}{ TRAINING 2 WEEKS PRIOR } & \multirow{2}{*}{$\begin{array}{c}\text { IPC } \\
\text { RETURN }\end{array}$} & \multicolumn{3}{|c|}{$\begin{array}{c}\text { MARKOWITZ PORTFOLIO } \\
\text { THEORY }\end{array}$} \\
\hline Buy & Sell & $\begin{array}{c}\text { Week } \backslash \\
\text { Portfolio }\end{array}$ & P8 & P9 & P10 & P11 & P12 & P13 & P14 & & $\begin{array}{l}\text { Maximize } \\
\text { return }\end{array}$ & $\begin{array}{c}\text { Zero } \\
\text { return }\end{array}$ & $\begin{array}{l}\text { Minimal } \\
\text { risk }\end{array}$ \\
\hline $\begin{array}{l}15 / 05 / 20 \\
20\end{array}$ & $22 / 05 / 2020$ & 1 & $6.50 \%$ & $7.20 \%$ & $7.90 \%$ & $8.59 \%$ & $9.29 \%$ & $9.99 \%$ & $\begin{array}{c}10.28 \\
\%\end{array}$ & $0.26 \%$ & $1.70 \%$ & $1.27 \%$ & $0.52 \%$ \\
\hline $\begin{array}{l}22 / 05 / 20 \\
20\end{array}$ & $29 / 05 / 2020$ & 2 & $1.09 \%$ & $1.00 \%$ & $0.90 \%$ & $0.81 \%$ & $0.72 \%$ & $0.63 \%$ & $0.54 \%$ & $0.94 \%$ & $-0.42 \%$ & $-0.49 \%$ & $0.15 \%$ \\
\hline $\begin{array}{l}29 / 05 / 20 \\
20\end{array}$ & $05 / 06 / 2020$ & 3 & $4.16 \%$ & $4.14 \%$ & $4.11 \%$ & $4.08 \%$ & $4.05 \%$ & $4.02 \%$ & $3.75 \%$ & $7.53 \%$ & $2.18 \%$ & $2.50 \%$ & $0.36 \%$ \\
\hline $\begin{array}{l}05 / 06 / 20 \\
20\end{array}$ & $12 / 06 / 2020$ & 4 & $-2.11 \%$ & $-2.32 \%$ & $-2.52 \%$ & $-2.74 \%$ & $-2.89 \%$ & $-2.87 \%$ & $-2.68 \%$ & $-3.31 \%$ & $0.70 \%$ & $1.90 \%$ & $1.20 \%$ \\
\hline & & $\begin{array}{l}\text { Cumulative } \\
\text { return }\end{array}$ & $9.64 \%$ & $10.02 \%$ & $10.38 \%$ & $10.75 \%$ & $11.18 \%$ & $11.78 \%$ & $\begin{array}{c}11.89 \\
\%\end{array}$ & $5.42 \%$ & $4.15 \%$ & $5.17 \%$ & $2.22 \%$ \\
\hline
\end{tabular}


Table 3. Comparison of weekly returns on training portfolios, part one.

\begin{tabular}{|c|c|c|c|c|c|c|c|c|c|c|c|c|c|}
\hline \multicolumn{2}{|c|}{ DATE } & \multicolumn{8}{|c|}{ CONTINUOUS TRAINING } & \multirow{2}{*}{$\begin{array}{c}\text { IPC } \\
\text { RETURN }\end{array}$} & \multicolumn{3}{|c|}{$\begin{array}{c}\text { MARKOWITZ PORTFOLIO } \\
\text { THEORY }\end{array}$} \\
\hline Buy & Sell & \begin{tabular}{c} 
Week\} $\\
{\text { Portfolio }}$ & P1 & P2 & P3 & P4 & P5 & P6 & P7 & & $\begin{array}{l}\text { Maximize } \\
\text { return }\end{array}$ & $\begin{array}{c}\text { Zero } \\
\text { return }\end{array}$ & $\begin{array}{l}\text { Minimal } \\
\text { risk }\end{array}$ \\
\hline $\begin{array}{l}15 / 05 / 20 \\
20\end{array}$ & $22 / 05 / 2020$ & 1 & $2.31 \%$ & $4.06 \%$ & $4.41 \%$ & $4.75 \%$ & $5.10 \%$ & $5.45 \%$ & $5.80 \%$ & $0.26 \%$ & $1.70 \%$ & $1.27 \%$ & $0.52 \%$ \\
\hline $\begin{array}{l}22 / 05 / 20 \\
20\end{array}$ & $29 / 05 / 2020$ & 2 & $1.71 \%$ & $3.54 \%$ & $3.39 \%$ & $3.11 \%$ & $2.79 \%$ & $2.48 \%$ & $2.17 \%$ & $0.94 \%$ & $-0.42 \%$ & $-0.49 \%$ & $0.15 \%$ \\
\hline $\begin{array}{l}29 / 05 / 20 \\
20\end{array}$ & $05 / 06 / 2020$ & 3 & $5.74 \%$ & $5.64 \%$ & $5.54 \%$ & $5.43 \%$ & $5.33 \%$ & $5.23 \%$ & $5.12 \%$ & $7.53 \%$ & $2.18 \%$ & $2.50 \%$ & $0.36 \%$ \\
\hline $\begin{array}{l}05 / 06 / 20 \\
20\end{array}$ & $12 / 06 / 2020$ & 4 & $0.22 \%$ & $-0.16 \%$ & $-0.54 \%$ & $-0.92 \%$ & $-1.30 \%$ & $-1.68 \%$ & $-2.06 \%$ & $-3.31 \%$ & $0.70 \%$ & $1.90 \%$ & $1.20 \%$ \\
\hline & & $\begin{array}{l}\text { Cumulative } \\
\text { return }\end{array}$ & $9.98 \%$ & $13.07 \%$ & $12.79 \%$ & $12.37 \%$ & $11.93 \%$ & $11.48 \%$ & $\begin{array}{c}11.03 \\
\%\end{array}$ & $5.42 \%$ & $4.15 \%$ & $5.17 \%$ & $2.22 \%$ \\
\hline
\end{tabular}
\end{tabular}

Source: Own creation in Excel with data from Yahoo Finances.

Table 4. Comparison of weekly returns on training portfolios, part two.

\begin{tabular}{|c|c|c|c|c|c|c|c|c|c|c|c|c|c|}
\hline \multicolumn{2}{|c|}{ DATE } & \multicolumn{8}{|c|}{ CONTINUOUS TRAINING } & \multirow{2}{*}{$\begin{array}{c}\text { IPC } \\
\text { RETURN }\end{array}$} & \multicolumn{3}{|c|}{$\begin{array}{c}\text { MARKOWITZ PORTFOLIO } \\
\text { THEORY }\end{array}$} \\
\hline Buy & Sell & $\begin{array}{c}\text { Week } \backslash \\
\text { Portfolio }\end{array}$ & P8 & P9 & P10 & P11 & P12 & P13 & P14 & & $\begin{array}{l}\text { Maximize } \\
\text { return }\end{array}$ & $\begin{array}{c}\text { Zero } \\
\text { return }\end{array}$ & $\begin{array}{l}\text { Minimal } \\
\text { risk }\end{array}$ \\
\hline $\begin{array}{l}15 / 05 / 20 \\
20\end{array}$ & $22 / 05 / 2020$ & 1 & $6.50 \%$ & $7.20 \%$ & $7.90 \%$ & $8.59 \%$ & $9.29 \%$ & $9.99 \%$ & $\begin{array}{c}10.28 \\
\% \\
\end{array}$ & $0.26 \%$ & $1.70 \%$ & $1.27 \%$ & $0.52 \%$ \\
\hline $\begin{array}{l}22 / 05 / 20 \\
20\end{array}$ & $29 / 05 / 2020$ & 2 & $1.86 \%$ & $1.54 \%$ & $1.23 \%$ & $1.16 \%$ & $1.05 \%$ & $0.42 \%$ & $-0.56 \%$ & $0.94 \%$ & $-0.42 \%$ & $-0.49 \%$ & $0.15 \%$ \\
\hline $\begin{array}{l}29 / 05 / 20 \\
20\end{array}$ & $05 / 06 / 2020$ & 3 & $5.02 \%$ & $4.92 \%$ & $4.81 \%$ & $4.71 \%$ & $4.42 \%$ & $4.03 \%$ & $3.78 \%$ & $7.53 \%$ & $2.18 \%$ & $2.50 \%$ & $0.36 \%$ \\
\hline \multirow[t]{2}{*}{$\begin{array}{l}05 / 06 / 20 \\
20 \\
\end{array}$} & $12 / 06 / 2020$ & 4 & $-2.35 \%$ & $-2.50 \%$ & $-2.53 \%$ & $-2.67 \%$ & $-2.82 \%$ & $-2.79 \%$ & $-2.68 \%$ & $-3.31 \%$ & $0.70 \%$ & $1.90 \%$ & $1.20 \%$ \\
\hline & & $\begin{array}{c}\text { Cumulative } \\
\text { return }\end{array}$ & $11.03 \%$ & $11.16 \%$ & $11.40 \%$ & $11.80 \%$ & $11.94 \%$ & $11.65 \%$ & $\begin{array}{c}10.83 \\
\%\end{array}$ & $5.42 \%$ & $4.15 \%$ & $5.17 \%$ & $2.22 \%$ \\
\hline
\end{tabular}


In week three the portfolio showed the best results of the study period. The market increased $7.31 \%$ this week, and only the P1 portfolio improved this growth with a $10.85 \%$ return which represents $3.32 \%$ more gains in the fuzzy portfolio. On the other hand, all the portfolios based on the proposed method exceed returns compared to those obtained with the conventional portfolio theory, being $2 \%$ the minimum profitability with which the proposed models exceed the Markowitz ones. However, the P2 to P7 portfolios all had lower results than the market.

On the other hand, week four was the week that generated the largest losses in the period studied. The market had a fall of $3.31 \%$ weekly, however, any portfolio in table 1 generated a loss as big as the market, being P7 the portfolio with the biggest negative return with $1.69 \%$ which represents a loss of $1.62 \%$ less than the market. Besides, the P1 and P2 portfolios are the only ones that generated gains from those built with the proposed methodology. However, this week Markowitz portfolios showed better results being the portfolio with zero return the one that had a $1.90 \%$ gain.

Table 2 is the continuation of the portfolios without an update in the training of the fuzzy neural network. These correspond to P8 to P14, in week one was found the second portfolio that had the best gains, of the period of analysis, which was P14 with $10.28 \%$, in this same week all the portfolios of the proposed methodology provided better results in comparison with the conventional models and the market. In week two this behavior is different for this set of portfolios, as only P8 and P9 improve market growth, but all 7 portfolios have higher returns than Markowitz portfolios.

In week 3 the performance of P8 to P14 was lower than the market but higher than that of the Markowitz portfolios. In this case, the portfolio's return range was $3.75 \%$ to $4.16 \%$; therefore, portfolios that target lower expected returns provide higher returns than those with high expected returns.

Tables 3 and 4 show the portfolios with neural network training. This means that each week the forecast of fuzzy neural networks was made considering the information of the last week that the financial assets were listed. For example, week-one was forecasted with information until May 15, week-two with information until May 22, week three with the quotes of the assets that correspond to the week that closed on May 29, and finally, week four has the fuzzy neural network forecasts with information until June 5. Therefore, all the synaptic weights of the neuronal networks are different each week.

Table 3 shows the portfolios with training corresponding to the 7 th with the lowest expected returns; week-one is the same in the two types of networks used to generate forecasts, considering that there is no update of the information. The changes can be observed from the second week, where the portfolios with neural network training provide the best results for this week being P2 the best portfolio with the profitability of 3.54\%, greater than the Markowitz methodology and the market.

Table 4 shows the results of the seven portfolios with the highest expected returns from the fuzzy neural network portfolios with training. The main results are shown in weeks 2 and 3, in which the distribution of assets by fuzzy neural networks demonstrates higher returns than the Markowitz model.

Finally, the conditions of the Mexican stock market have allowed for the optimal application of the Diffuse Neuronal Network, which allows for accurate predictions on the selected portfolio. In 
addition, the proposed method is a short-term model, because the fuzzy forecast is efficient in the first 10 days.

Thus, our method comes into the field of speculative investment and participates with methods such as Technical Analysis and Portfolio Theory. In the case of technical analysis, our technique also finds patterns in stock prices, but it exceeds the results provided by the technical analysis method because it provides the percentage of investment per asset. And Portfolio Theory, differs in the recognition of price volatility, so the results offered by the proposed process provide a higher return.

\section{Conclusion and recommendation}

The main conclusion of this research is that the model of portfolio selection based on fuzzy neural networks offers better results than the traditional method of portfolios. The reason is that the fuzzy neural networks provide early information on the behavior of asset price volatility, thereby allowing the selection of the assets with the highest expected returns.

This document proposes an alternative for the selection of portfolios. The model developed presents a modification of the main assumption of the portfolio theory, the expected return, and the risk, which consists in that the source of risk and the measurement of the return is projected through diffuse neural networks.

In other words, the expected return of this model is measured through the projection of financial stock prices, and the risk is analyzed through the projection error. The selection of the assets in the portfolio maintains the same optimization problem, where only the sources of information change, so the technique presented does not use the variance-covariance matrix or the historical mean return.

In the period of study, the accumulated return of the proposed model provided up to $300 \%$ higher profitability than the Markowitz method and market growth. The fuzzy portfolio that obtained the highest returns is the P1 without training with an accumulated return of $15.68 \%$ in four weeks, so, the market generated an accumulated return of $5.42 \%$, and the portfolio of maximum return generated an accumulated return of $4.15 \%$. These results provide evidence that the proposed technique allows the identification of investment portfolios with better returns compared to the Markowitz model and the growth of the Mexican market.

The study found 3 models that did not have negative returns, P1 with training had a return of 9.98\%, the portfolio without training P1 was $15.68 \%$, and the portfolio with minimum variance Markowitz with a cumulative return of $2.22 \%$. The risk-minimization model then generated gains at the end of the period, however, the Markowitz technique provided significantly less return than the proposed portfolios. Therefore, we concluded that the optimal portfolio is P1 because it has the best risk-return combination of the portfolios analyzed.

The improvement in the estimation of the models presented is attributed to the incorporation of a primary element within the fuzzy theory, that is, the membership function. In these methods, the membership function is considered as a classifier of volatility, which plays a very important role in the forecast of the time series, supported in the identification of the degrees of uncertainty associated with the diverse economic, political, and social conditions that can impact in the behavior of the stock market. 
A key result is that the application of fuzzy theory within the traditional neural network methodology generates a relevant contribution in the study of the non-linearity of financial time series. This is attributed to the fact that the proposed models better recognize the uncertainty of variables with high volatility in their behavior because the combination of both methodologies generates classified learning of the existing uncertainty in the time series to achieve more accurate forecasts.

The main contribution of this research is the proposed new methodology for portfolio selection, which allows investors to select investment portfolios with higher returns compared to Markowitz's portfolio theory and general market results. Therefore, the portfolio selection methodology with fuzzy neural networks allows stock market investors to maximize their investments by identifying combinations of stocks that generate higher returns.

Thus, the proposed method allows investment managers to find the portfolios that will maximize the return on savings and capital for economic agents in Mexico. This allows for maximizing returns on workers' savings, family savings, corporate investments, government funds, corporate cash management, etc. In other words, this new technique allows for greater returns on the resources of Mexican society.

The recommendation of this study is to replicate the proposed methodology for other periods and financial assets in the Mexican market. Also, to diversify the terms and types of financial instruments, in the Mexican market and another market. In this way, ensure better risk management, with a model that provides higher returns.

\section{References}

[1] Calvo, C., Ivorra, C., \& Liern, V. (2014). Fuzzy portfolio selection with non-financial goals exploring the efficient frontier. Annals of Operations Research. Doi:10.1007/s10479-014-1561-2

[2] Chen, S. M., \& Hsu, C. C. (2004). A new method to forecast enrollments using fuzzy time series. International Journal of Applied Science and Engineering, 2(3), pp. 234-244.

[3] Chen, B., Zhong, J., \& Chen, Y. (2020). A hybrid approach for portfolio selection with higher-order moments: Empirical evidence from Shanghai Stock Exchange. Expert Systems with Applications, 145, 113104. Doi: https://doi.org/10.1016/j.eswa.2019.113104

[4] Cox, E. (2019). The Fuzzy Systems Handbook: A Practitioner s Guide to Building, Using, and Maintaining Fuzzy Systems/Book and Disk.

[5] Dash, R., \& Dash, P. (2016). An evolutionary hybrid Fuzzy Computationally Efficient EGARCH model for volatility prediction. Applied Soft Computing, pp. 40-60. Doi: https://doi.org/10.1016/j.asoc.2016.04.014

[6] Egrioglu, E., Aladag, C. H., \& Yolcu, U. (2013). Fuzzy time series forecasting with a novel hybrid approach combining fuzzy c-means and neural networks. Expert Systems with Applications, pp. 854857. Doi: https://doi.org/10.1016/j.eswa.2012.05.040

[7] Egrioglu, E., Aladag, C. H., Yolcu, U., Basaran, M. A., \& Uslu, V. R. (2009). A new hybrid approach based on SARIMA and partial high order bivariate fuzzy time series forecasting model. Expert Systems with Applications, 36(4), pp. 7424-7434. Doi: https://doi.org/10.1016/j.eswa.2008.09.040 
[8] Fernández, A., \& Gómez, S. (2007). Portfolio selection using neural networks. Computers \& Operations Research, 1177-1191. Doi: 10.1016/j.cor.2005.06.017

[9] Galankashi, M. R., Rafiei, F. M., \& Ghezelbash, M. (2020). Portfolio selection: a fuzzy-ANP approach. Financial Innovation, 6(1), 1-34. Doi: https://doi.org/10.1186/s40854-020-00175-4

[10] García, J., López, A. M., Romero, J., García, A. R., Camacho, C., Cantero, J. L., Salas, R. (2002). Hojas de Cálculo para la Simulación de Redes Neuronales Artificiales. Questtió, 26, pp. 289-305.

[11] Gong, X., Yu, C., Min, L., \& Ge, Z. (2021). Regret theory-based fuzzy multi-objective portfolio selection model involving DEA cross-efficiency and higher moments. Applied Soft Computing, 100, 106958. Doi: https://doi.org/10.1016/j.asoc.2020.106958

[12] Guo, S., Ching, W. K., Li, W. K., Siu, T. K., \& Zhang, Z. (2020). Fuzzy hidden Markov-switching portfolio selection with capital gain tax. Expert Systems with Applications, 149, 113304. Doi: https://doi.org/10.1016/j.eswa.2020.113304

[13] Han, M., Zhong, K., \& Han., B. (2018). Interval Type-2 Fuzzy Neural Networks for Chaotic Time Series Prediction: A Concise Overview. IEEE Transactions on Cybernetics, pp. 1-12. Doi: https://doi.org/10.1109/tcyb.2018.2834356

[14] Huang, X. (2008). Mean-semi variance models for fuzzy portfolio selection. Journal of Computational and Applied Mathematics, 1-8.

[15] Ishibuchi, H., \& Tanaka, H. (1992). Fuzzy regression analysis using neural networks. Fuzzy sets and systems, 50(3), pp. 257-265. Doi: https://doi.org/10.1016/0165-0114(92)90224-r

[16] Iqbal, J., Sandhu, M. A., Amin, S., \& Manzoor, A. (2019). Portfolio Selection and Optimization through Neural Networks and Markowitz Model: A Case of Pakistan Stock Exchange Listed Companies. Review of Economics and Development Studies, 183-196. Doi: 10.26710/reads.v5i1.354

[17] Jang, J. R. (1993). ANFIS: Adaptive-Network-Based Fuzzy Inference System. IEEE Transactions on Systems, pp.665-685. Doi: https://doi.org/10.1109/21.256541

[18] Kar, M. B., Kar, S., Guo, S., Li, X., \& Majumder, S. (2018). A new bi-objective fuzzy portfolio selection model and its solution through evolutionary algorithms. Soft Computing. Doi: 10.1007/s00500-0183094-0

[19] Khanjani Shiraz, R., Tavana, M., \& Fukuyama, H. (2020). A random-fuzzy portfolio selection DEA model using value-at-risk and conditional value-at-risk. Soft Computing, 24, 167-186. Doi: https://doi.org/10.1007/s00500-020-05010-7

[20] Ko, P.-C., \& Lin, P.-C. (2008). Resource allocation neural network in portfolio selection. Expert Systems with Applications, 330-337. Doi:10.1016/j.eswa.2007.07.031

[21] Li, W., \& Deng, X. (2020). Multi-parameter portfolio selection model with some novel score-deviation under dual hesitant fuzzy environment. International Journal of Fuzzy Systems, 22(4), 1123-1141. Doi: https://doi.org/10.1007/s40815-020-00835-8

[22] Markowitz, H. (1952 ). Modern portfolio theory. Journal of Finance, 77-91.

[23] Markowitz, H. M. (1991). Foundations of Portfolio Theory. Journal of Finance, 469-477.

[24] Medina-Reyes, J. E., Castro-Pérez, J. J., Cabrera-Llanos, A. I., \& Cruz-Aké, S. (2020). Red neuronal autorregresiva difusa tipo Sugeno con funciones de membresía triangular y trapezoidal: una aplicación al pronóstico de índices del mercado bursátil. Estocástica: FINANZAS Y RIESGO, pp. 77-101. Obtenido de http://revistastmp.azc.uam.mx/estocastica/index.php/re/article/view/130

[25] Medina-Reyes, J. E. (2019). Studies of Fuzzy Time Series Models: An Application to the Forecast Exchange Rate, Mexican Peso/ American Dollar. ResearchGate. (I. P. N., Ed.), Thesis for: Master of Science, Advisor: Salvador Cruz Aké; Agustín Ignacio Cabrera Llanos, Doi:10.13140/RG.2.2.21331.53288.

[26] Mohammadian, M. (2020). Modeling, control, and prediction using hierarchical fuzzy logic systems: Design and development. In Robotic Systems: Concepts, Methodologies, Tools, and Applications (pp. 
REMEF (The Mexican Journal of Economics and Finance)

Fuzzy Portfolio Selection with Sugeno Type Fuzzy Neural Network: Investing in the Mexican Stock Market

187-207). IGI Global.Pal, S. S., \& Kar, S. (2017). Fuzzy Time Series Model for Unequal Interval Length Using Genetic Algorithm. Advances in Intelligent Systems and Computing, pp. 205-216. Doi: https://doi.org/10.4018/978-1-7998-1754-3.ch009

[27] Pal, S. S., \& Kar, S. (2018). A Hybridized Forecasting Method Based on Weight Adjustment of Neural Network Using Generalized Type-2 Fuzzy Set. International Journal of Fuzzy Systems, pp. 1-13. Doi: https://doi.org/10.1007/s40815-018-0534-z

[28] Raei, R. (2006). Risky Portfolio Selection through Neural Networks. Iranian Accounting \& Auditing Review, 70-83.

[29] Ramli, S., \& Jaaman, S. H. (2019). Several Extended Mean-variance Fuzzy Portfolio Selection Models Based on Possibility Theory. International Symposium on Geometric Function Theory and Applications. Doi:10.1088/1742-6596/1212/1/012027

[30] Rossi, G. D. (2013). La Volatilidad en Mercados Financieros y de Commodities. Un Repaso de sus Causas y la Evidencia Reciente. Invenio, pp. 59-74.

[31] Shiraz, R. K., Tavana, M., \& Fukuyama, H. (2020). A random-fuzzy portfolio selection DEA model using value-at-risk and conditional value-at-risk. Soft Computing. doi:10.1007/s00500-020-05010-7

[32] Singh, P. (2017). A brief review of modeling approaches based on fuzzy time series. International Journal of Machine Learning and Cybernetics, 8(2), pp. 397-420. Doi: https://doi.org/10.1007/s13042-015-0332-y

[33] Song, Q., \& Chissom, B. S. (1993a). Fuzzy time series and its models. Fuzzy Sets and Systems, 54, pp. 269-277. Doi: https://doi.org/10.1016/0165-0114(93)90372-o

[34] Song, Q., \& Chissom, B. S. (1993b). Forecasting enrollments with fuzzy time series - Part I. Fuzzy Sets and Systems, 54, pp. 1-9. Doi: https://doi.org/10.1016/0165-0114(93)90355-l

[35] Song, Q., \& Chissom, B. S. (1994). Forecasting enrollments with fuzzy time series part II. Fuzzy Sets and Systems, 62, pp. 1-8. Doi: https://doi.org/10.1016/0165-0114(94)90067-1

[36] Souza, P. V., \& Torres, L. C. (2018). Regularized Fuzzy Neural Network Based on Or Neuron for Time Series Forecasting. Springer International Publishing AG, part of Springer Nature, pp. 13-23.

[37] Srinivasan, \& Lakshmi. (2019). Stock Price Prediction Using Fuzzy Time-Series Population-Based Gravity Search Algorithm. International Journal of Software Innovation, pp. 50-64. Doi: https://doi.org/10.4018/ijsi.2019040105

[38] Tsaur, R.-C. (2012). A Fuzzy Time Series-Markov Chain Model with an Application to Forecast the Exchange Rate Between the Taiwan and US Dollar. International Journal of Innovative Computing, Information, and Control, 8, pp. 4931-4942.

[39] Tseng, F.-M., \& Tzeng, G.-H. (2002). A fuzzy seasonal ARIMA model for forecasting. Fuzzy Sets and Systems, 126, pp. 367-376. Doi: https://doi.org/10.1016/s0165-0114(01)00047-1

[40] Tseng, F.-M., Tzeng, G.-H., Yu, H.-C., \& Yuan, B. J. (2001). Fuzzy ARIMA model for forecasting the foreign exchange market. Fuzzy Sets and Systems, 118, pp. 9-19.Doi: https://doi.org/10.1016/s01650114(98)00286-3

[41] Wu, S., \& Er, M. J. (2000). Dynamic Fuzzy Neural Networks; A Novel Approach to Function Approximation. IEEE Transactions on Systems, Man, and Cybernetics, pp. 358-364. Doi: https://doi.org/10.1109/3477.836384

[42] Xiao, Q. (2017). Time Series Prediction Using Bayesian Filtering Model and Fuzzy Neural Networks. International Journal for Light and Electron Optics, pp. 1-20.

[43] Yu, H.-K. (2005). Weighted fuzzy time series models for TAIEX forecasting. Physica A: Statistical Mechanics and its Applications, 349, pp. 609-624. Doi: https://doi.org/10.1016/j.physa.2004.11.006

[44] Yu, Y., Deng, X., Chen, C., \& Cheng, K. (2020). Research on Fuzzy Multi-objective Multi-period Portfolio by Hybrid Genetic Algorithm with Wavelet Neural Network. Engineering Letters. 
[45] Yu, T. H.-K., \& Huarng, K.-H. (2010). A neural network-based fuzzy time series model to improve forecasting. Expert Systems with Applications, pp. 3366-3372. Doi: https://doi.org/10.1016/j.eswa.2009.10.013

[46] Zhang, X., Fang, L., Hipel, K. W., Ding, S., \& Tan, Y. (2020). A hybrid project portfolio selection procedure with historical performance consideration. Expert Systems with Applications, 142, 113003. Doi: https://doi.org/10.1016/j.eswa.2019.113003 